\title{
Flow-induced, inflammation-mediated arterial wall remodeling in the formation and progression of intracranial aneurysms
}

\author{
*Juhana Frösen, MD, PhD, ${ }^{1,2}$ Juan Cebral, $\mathrm{PhD},{ }^{3}$ Anne M. Robertson, $\mathrm{PhD},{ }^{4}$ and \\ Tomohiro Aoki, MD, PhD 5,6
}

1Department of Neurosurgery, and ${ }^{2}$ Hemorrhagic Brain Pathology Research Group, Kuopio University Hospital, Kuopio, Finland; ${ }^{3}$ Bioengineering Department, Volgenau School of Engineering, George Mason University, Fairfax, Virginia; ${ }^{4}$ Department of Mechanical Engineering and Materials Science, University of Pittsburgh, Pittsburgh, Pennsylvania; and ${ }^{5}$ Department of Molecular Pharmacology, Research Institute, and ${ }^{6}$ Core Research for Evolutional Science and Technology (CREST) from Japan Agency for Medical Research and Development (AMED), National Cerebral and Cardiovascular Center, Suita, Osaka, Japan

OBJECTIVE Unruptured intracranial aneurysms (UIAs) are relatively common lesions that may cause devastating intracranial hemorrhage, thus producing considerable suffering and anxiety in those affected by the disease or an increased likelihood of developing it. Advances in the knowledge of the pathobiology behind intracranial aneurysm (IA) formation, progression, and rupture have led to preclinical testing of drug therapies that would prevent IA formation or progression. In parallel, novel biologically based diagnostic tools to estimate rupture risk are approaching clinical use. Arterial wall remodeling, triggered by flow and intramural stresses and mediated by inflammation, is relevant to both.

METHODS This review discusses the basis of flow-driven vessel remodeling and translates that knowledge to the observations made on the mechanisms of IA initiation and progression on studies using animal models of induced IA formation, study of human IA tissue samples, and study of patient-derived computational fluid dynamics models.

RESULTS Blood flow conditions leading to high wall shear stress (WSS) activate proinflammatory signaling in endothelial cells that recruits macrophages to the site exposed to high WSS, especially through macrophage chemoattractant protein 1 (MCP1). This macrophage infiltration leads to protease expression, which disrupts the internal elastic lamina and collagen matrix, leading to focal outward bulging of the wall and IA initiation. For the IA to grow, collagen remodeling and smooth muscle cell (SMC) proliferation are essential, because the fact that collagen does not distend much prevents the passive dilation of a focal weakness to a sizable IA. Chronic macrophage infiltration of the IA wall promotes this SMC-mediated growth and is a potential target for drug therapy. Once the IA wall grows, it is subjected to changes in wall tension and flow conditions as a result of the change in geometry and has to remodel accordingly to avoid rupture. Flow affects this remodeling process.

CONCLUSIONS Flow triggers an inflammatory reaction that predisposes the arterial wall to IA initiation and growth and affects the associated remodeling of the UIA wall. This chronic inflammation is a putative target for drug therapy that would stabilize UIAs or prevent UIA formation. Moreover, once this coupling between IA wall remodeling and flow is understood, data from patient-specific flow models can be gathered as part of the diagnostic workup and utilized to improve risk assessment for UIA initiation, progression, and eventual rupture.

https://thejns.org/doi/abs/10.3171/2019.5.FOCUS19234

KEYWORDS intracranial aneurysm; flow; inflammation; remodeling; risk of rupture

ABBREVIATIONS aSAH = aneurysmal subarachnoid hemorrhage; bAVM = brain arteriovenous malformation; CFD = computational fluid dynamics; COX2 = cyclooxygenase 2; EC = endothelial cell; eNOS = endothelial NO synthase; IA = intracranial aneurysm; IEL = internal elastic lamina; MCP1 = macrophage chemotactic protein 1; NFkB = nuclear factor kappa $\mathrm{b} ; \mathrm{NO}=$ nitric oxide; PDGF-B = platelet-derived growth factor $\mathrm{B} ; \mathrm{PGE}_{2}=$ prostaglandin $\mathrm{E} 2$; PPAR = peroxisome proliferator-activated receptor; SMC = smooth muscle cell; TGFb = transforming growth factor beta; UIA = unruptured IA; VCAM1 = vascular cell adhesion molecule 1 ; WSS = wall shear stress; WSSG = WSS gradient; $\mathrm{WT}=$ wall tension .

SUBMITTED March 3, 2019. ACCEPTED May 1, 2019.

INCLUDE WHEN CITING DOI: 10.3171/2019.5.FOCUS19234.

${ }^{*}$ A.M.R. and T.A. contributed equally to this work. 
$\mathrm{U}$ NRUPTURED intracranial aneurysms (UIAs) are found increasingly often as incidental findings during intracranial MR- or CT-angiographic imaging due to better availability of these studies. ${ }^{22}$ Because incidentally found UIAs may later rupture, causing devastating aneurysmal subarachnoid hemorrhage (aSAH), ${ }^{22}$ many patients with incidental UIAs are anxious and want their aneurysms treated. Current treatment options are all interventions with nonnegligible risk of morbidity and even mortality. ${ }^{45,54}$ As a consequence, physicians treating UIAs are challenged with the assessment of whether the rupture risk of an incidental UIA justifies the risks associated with treatment. ${ }^{21}$ This task is complex and demanding because multiple factors impacting the risk of UIA rupture have been identified,,$^{21,31,69,72}$ but no absolute threshold values have been identified for any of these established risk factors to discriminate stable UIAs from those that progress toward rupture..$^{50}$

UIAs are relatively frequent lesions, with $3 \%$ or higher prevalence in the population older than middle age. ${ }^{22}$ The clearly lower prevalence of UIAs in children or young adults in population-based studies and clinical series, ${ }^{60}$ together with the fact that formation of new UIAs (so called de novo aneurysms) is observed during follow-up of patients, ${ }^{51}$ demonstrates that UIAs are not innate lesions but develop during life. This implies that UIA formation is the end result of degenerative cerebral arterial wall remodeling. Understanding the biology of this remodeling process is the key to identification and rational management of persons at risk of UIA formation, as well as those who have been diagnosed with UIAs. The fact that many, if not most, UIAs remain unruptured during lifelong follow-up ${ }^{43}$ demonstrates that there is also adaptive remodeling that can stabilize the UIA wall and ensure sufficient strength to withstand the mechanical stress imposed on the aneurysm wall by blood pressure and flow. ${ }^{58}$ Understanding the mechanisms mediating the destructive and adaptive remodeling of the cerebral artery and aneurysm wall will open the door for the design and development of pharmaceutical or other biological therapies that would inhibit UIA formation and progression toward rupture. This development would thus offer new hope for those at risk of UIA formation (such as persons with familial predisposition to $\mathrm{aSAH}^{22}$ ) and in some cases be an alternative to invasive UIA treatment.

\section{Aneurysm Formation, Active Collagen Remodeling, and Disruption of Elastic Laminas}

The wall of normal intracranial arteries is composed of a luminal endothelial cell (EC) layer, underneath which is the basal lamina composed of matrix proteins, then the internal elastic lamina (IEL) composed of elastic fibers, followed by the media layer composed of smooth muscle cells (SMCs), elastic laminas, and collagen fibers. ${ }^{29,59}$ The adventitia layer starts at the outer rim of the media, and is composed of collagen fibers and fibroblast cells. All the components of the arterial wall have specific functions, of which resistance to mechanical stretch and maintenance of structural integrity are almost entirely due to the elastic laminas and the medial and adventitial collagen fibers. ${ }^{59,71}$ Unlike the elastic laminas that distend when loaded to absorb and then release part of the energy of the pulse wave, ${ }^{59,71}$ collagen fibers have little capacity for extension prior to failure..$^{30}$ The collagen fibers in the medial layer of the arterial wall are undulated in the unloaded state and straighten during normal physiological cyclic loading. ${ }^{36}$ The degree of tortuosity of the collective collagen fibers in the medial and adventitial layers determines how much the artery can distend and protects the artery from overstretching. Loss of elastic laminas is characteristic of aneurysms ${ }^{27,29,58}$ and shifts greater load bearing to the collagen fibers, which diminishes the tortuosity of the collagen fibers and limits the capacity of the vessel to dilate. ${ }^{58}$

Because collagen fibers are relatively inextensible compared with elastin,,$^{30,71}$ growth of an aneurysm-sometimes up to a size multiple times the original diameter of the parent artery-requires remodeling of the collagen fibers in the aneurysm wall. ${ }^{58}$ Collagen is the main load-bearing structure in the vessel wall once the elastic laminas are lost, therefore the end result of this collagen remodeling determines the strength of the aneurysm wall, and thus also the conditions that suffice for rupture. ${ }^{58}$ Not surprisingly, there is high variation in the strength of the aneurysm wall when measured under standardized laboratory conditions, with both robust and vulnerable groups within the UIAs and, on average, ruptured intracranial aneurysms (IAs) having weaker walls than UIAs. ${ }^{58}$ Of great interest is the striking observation that remodeled collagen fibers in the aneurysm wall are oriented according to flow and the wall shear stress (WSS) sensed by the EC layer. ${ }^{14}$ This raises the question of whether collagen remodeling in the aneurysm wall is guided by flow, a concept further supported by the observation that flow conditions in the aneurysm fundus associate with strength of the aneurysm wall.13

What makes these observations especially intriguing is the implication that by guiding the collagen remodeling of the aneurysm wall, flow would eventually determine how prone the aneurysm is to rupture, in addition to its impact on aneurysm formation and growth.

\section{Blood Flow as the Driver of Outward Remodeling in Vessels}

The idea that flow would guide the remodeling of blood vessel structure similarly to how mechanical load guides the remodeling of bone trabeculae is not new, and in fact was proposed as early as the $1960 \mathrm{~s}^{47}$ if not earlier. This idea is the underlying premise in studies of growth and remodeling in blood vessels. ${ }^{37}$ Surgical arteriovenous fistulas created to enable hemodialysis provide clear evidence that this flow-induced vessel remodeling takes place in humans. ${ }^{23,64}$ In these fistulas, the lack of capillary bed resistance produces an abnormally high flow, which leads to outward remodeling to a size multiple times larger than the original, especially in the draining vein ${ }^{64}$ also subjected to higher than intended pressure in addition to abnormally high flow. Experimental models of surgically created arteriovenous fistulas demonstrate that this flow-induced outward remodeling occurs through a coordinated 
sequence of protease expression followed by synthesis of new collagen. ${ }^{32,73}$ Underlying deficiency in elastic laminas accelerates this flow-induced outward vessel remodeling. ${ }^{73}$

\section{Effect of High Flow in Cerebral Arteries: Focal Outward Remodeling Leading to Aneurysm Formation}

Manipulation of cerebral blood flow by uni- or bilateral ligation of carotid arteries in laboratory animals predisposes to segmental or focal dilation and UIA formation at sites of the cerebral vasculature exposed by the procedure to abnormally high flow, especially if coupled with hypertension and defective collagen synthesis ${ }^{6,42,69}$ (Fig. 1). As in humans, these induced aneurysms develop preferably at bifurcations (reviewed in Aoki and Nishimura; ${ }^{6}$ Fig. 1). Although de novo IA formation is occasionally observed in clinical practice after uni- or bilateral carotid occlusion due to disease or medical procedure, overall the prevalence of UIAs in patients with occlusive carotid artery diseases $(3 \%)^{41}$ seems similar to the general population. ${ }^{22}$ This apparent controversy between the animal models and clinical observations can be explained by slower development of the clinical disease, which allows time for collateral circulation to develop. Moreover, differences in the magnitude of flow enhancement obtained with carotid ligation in animals compared to carotid occlusion in humans is likely relevant. A more direct proof of flowinduced vessel remodeling causing aneurysm initiation in humans is obtained from patients with arteriovenous malformations of the brain (bAVMs). Brain AVMs cause similar arteriovenous shunting as surgically created arteriovenous fistulas, and many of the bAVM feeding arteries that are exposed to abnormally high flow develop segmental ectasia or saccular aneurysms. ${ }^{49,67}$ Of special interest is the observation that some of these bAVM-associated IAs spontaneously regress once the shunting lesion is obliterated and flow normalized, ${ }^{49}$ demonstrating that these IAs are initiated and maintained by abnormally high flow.

\section{Inflammation as the Mediator of Flow-Induced Outward Remodeling and Aneurysm Initiation}

Classic work by Langille in the 1980s demonstrated the capacity of the arterial wall to respond to both increases and decreases in flow through an initial acute vasomotor response, followed by wall remodeling. ${ }^{48}$ This adaptation to flow requires an intact endothelium. ${ }^{48}$ It is now understood that the surface proteoglycan layer (glycocalyx) on

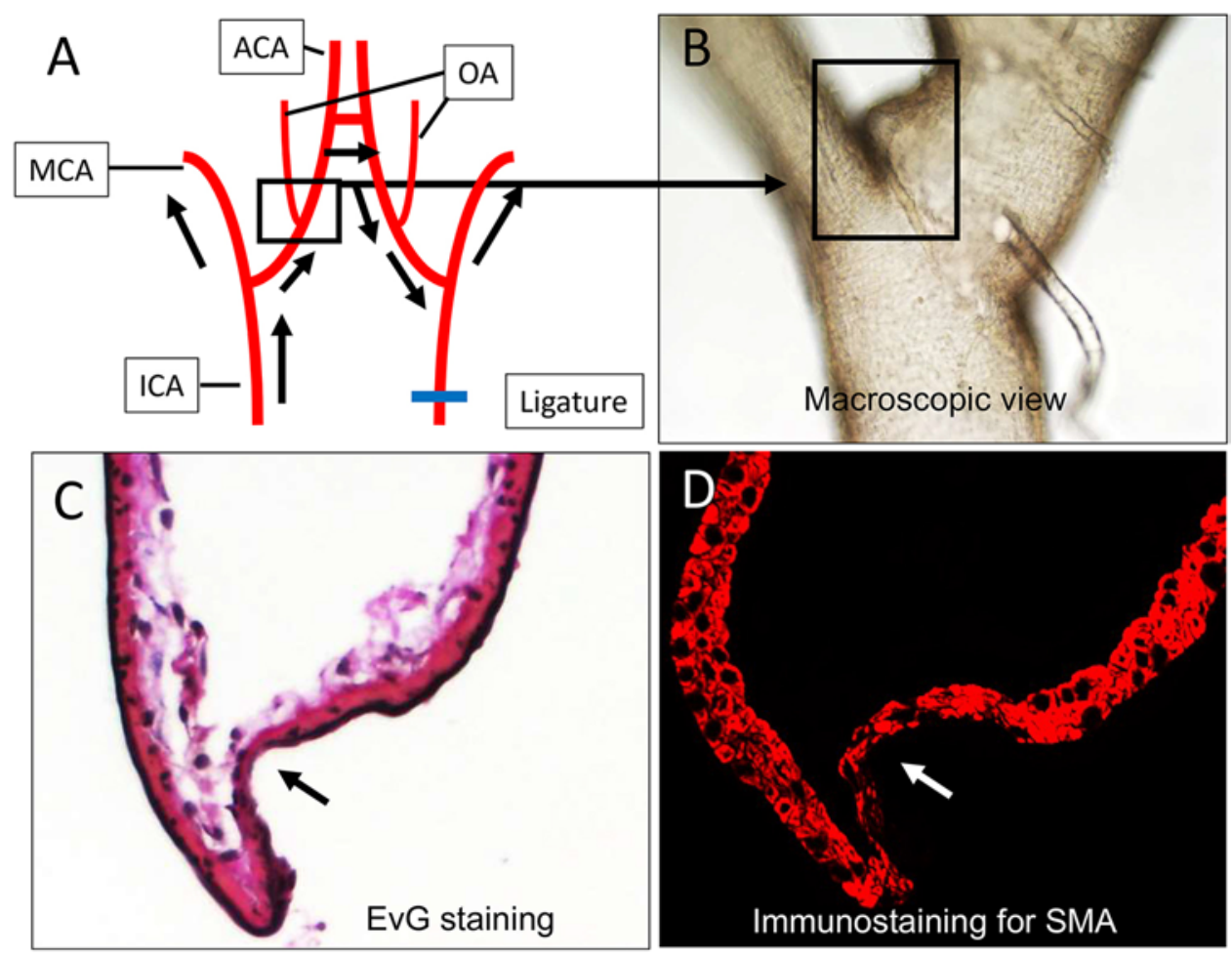

FIG. 1. The model of induced formation of IAs, established and developed by Nobuo Hashimoto, demonstrates in practice how increase in flow predisposes to IA formation. In this model, unilateral carotid artery ligation (A) coupled with induced hypertension and impaired collagen remodeling leads to IA initiation (A-D) at the contralateral bifurcation (black box) of the olfactory artery (OA) and the anterior cerebral artery (ACA) that are exposed to increased flow (black arrows in A) due to the demand of the arterial bed supplied by the ligated carotid artery (A). The site of IA initiation is characterized by disruption of the IEL (demonstrated with Elastica van Gieson [EvG] staining in C, arrow) and by thinning but not complete absence of the SMC layer (demonstrated with alpha-smooth muscle actin [SMA] staining in D, arrow). This ectatic (outward) vessel remodeling leading to IA initiation occurs mainly at apices of bifurcations (reviewed by Aoki and Nishimura, $2011^{6}$ ), unless injury to the elastic laminas is exacerbated by elastase infusion to the CSF. ICA = internal carotid artery; MCA = middle cerebral artery. 
the endothelium surface is the primary sensor of flowrelated forces. ${ }^{66}$ In particular, flow across the endothelial cells generates a WSS, a frictional force per unit area tangential to the flow.

WSS is primarily dependent on blood viscosity and flow velocity (Fig. 2). If the vessel diameter remains constant, increased volumetric flow rate increases the velocity, which in turn increases WSS (Fig. 2). The largest increases in WSS are generally noted at outer walls of curved vessel segments, highly constricted regions of arteries, and the apex regions of bifurcations. At these sites the local velocity is elevated due to the coupled nature of flow and geometry (reviewed in Tanweer et al. ${ }^{65}$ ). Using surgically created high-flow bifurcations, Meng et al. showed that the changes predisposing to aneurysm formation, namely IEL disruption and degeneration of the SMC layer, develop at the sites exposed to high WSS and to a positive WSS gradient (WSSG). ${ }^{53}$ Since then, several studies using various animal models have concluded that IA initiation occurs in regions exposed to high WSS with a positive WSSG. ${ }^{20}$

Nitric oxide (NO) produced by endothelial NO synthase (eNOS) is the primary mediator of the EC-triggered vasodilation in response to high flow. ${ }^{75}$ An increase in WSS induces eNOS production in ECs, in addition to relaxing the medial SMCs. ${ }^{57}$ This increase in NO downregulates the expression of the proinflammatory adhesion molecules macrophage chemotactic protein 1 (MCP1) and vascular cell adhesion molecule 1 (VCAM1) that are otherwise concomitantly upregulated in ECs in response to WSS. ${ }^{75}$ Experiments with NOS knockout mice demonstrate how blocking NOS signaling predisposes to IA formation through an increase in macrophage infiltration, presumably through increased MCP1 expression ${ }^{7}$ (Fig. 3). Recent results suggest that mechanical stretch can also induce MCP1 expression in adventitial fibroblasts, which promotes the transmural migration of macrophages. ${ }^{44} \mathrm{Co}-$ localization of high WSS with wall stretch would thus lead to amplified MCP1 expression and macrophage infiltration with increased likelihood of eventual IA initiation. ${ }^{44}$

The crucial role of MCP1 in aneurysm initiation is demonstrated by experiments with MCP1 knockout mice, in which macrophage infiltration was nearly absent in cerebral arteries exposed to high flow, and IA initiation and formation were reduced by more than half. ${ }^{3}$ The key role of macrophage infiltration in IA initiation has been confirmed by several other studies using variations of the classic induced-IA formation model and clodronate to deplete macrophages ${ }^{40,44,68}$ or manipulation of macrophage activation through peroxisome proliferator-activated receptor (PPAR) gamma. ${ }^{63}$

In the rodent models of induced-IA formation, macrophages infiltrate the arterial wall through the luminal endothelium during IA initiation. ${ }^{44}$ Next, they migrate through the wall, eventually reaching the adventitia following a chemotactic gradient generated by MCP1 expression in adventitial fibroblasts. ${ }^{44}$ Because transendothelial migration to the vessel wall has to occur through the IEL
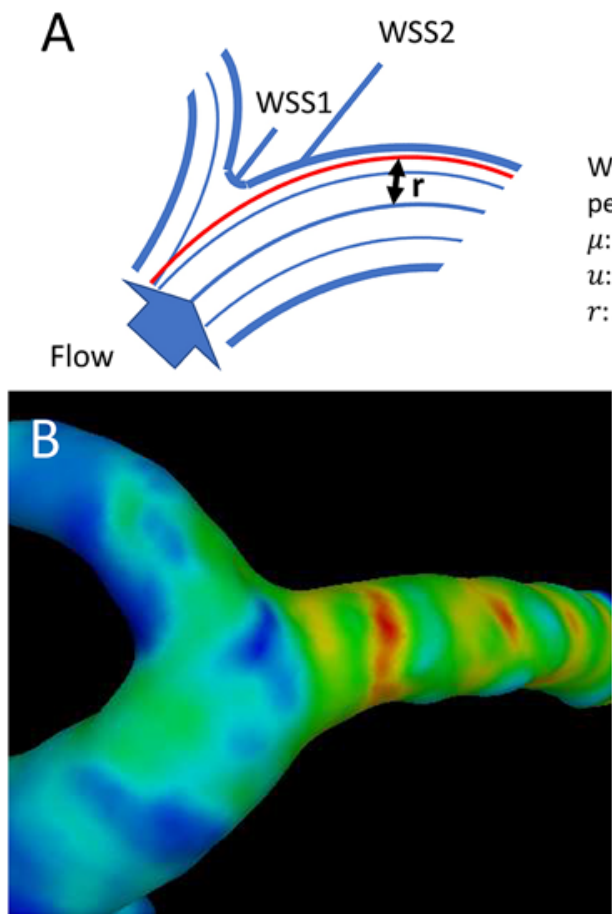

$$
\mathrm{WSS}=\mu \frac{\partial u}{\partial r}
$$

WSS: Wall shear stress, frictional force on the wall per unit area

$\mu$ : dynamic viscosity

$u$ : flow velocity in axial direction

$r$ : distance from the centerline of the vessel

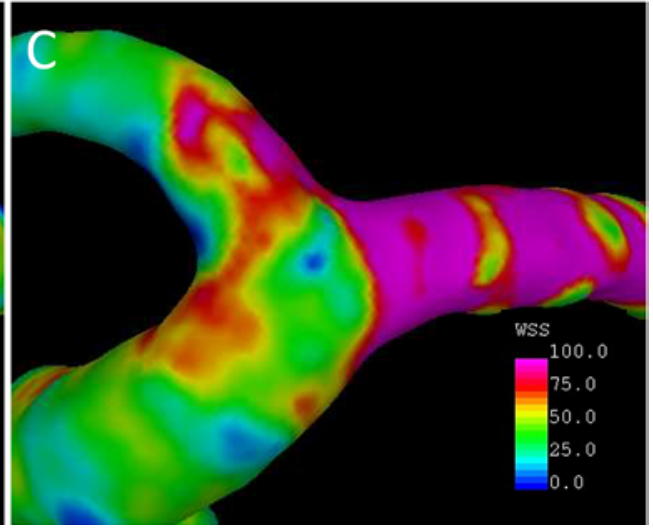

FIG. 2. WSS is a flow-induced force per unit area tangential to the direction of the flow and dependent on the rate of flow (A). Therefore, WSS at the apices of arterial bifurcations increases if flow increases, as demonstrated by the CFD modeling of WSS in patient-derived geometry of internal carotid artery bifurcation with low $(1.86 \mathrm{ml} / \mathrm{sec}, \mathrm{B})$ and high $(2.72 \mathrm{ml} / \mathrm{sec}, \mathrm{C})$ flows. While the shear stress is a vector that has both magnitude and direction, only one component is nonzero in the case shown in $A$, and in $B$ and $C$ the magnitude of the vector is shown in the form of contour plots. WSSG is the difference between WSS at two different sites on the vessel wall (WSS1-WSS2). 


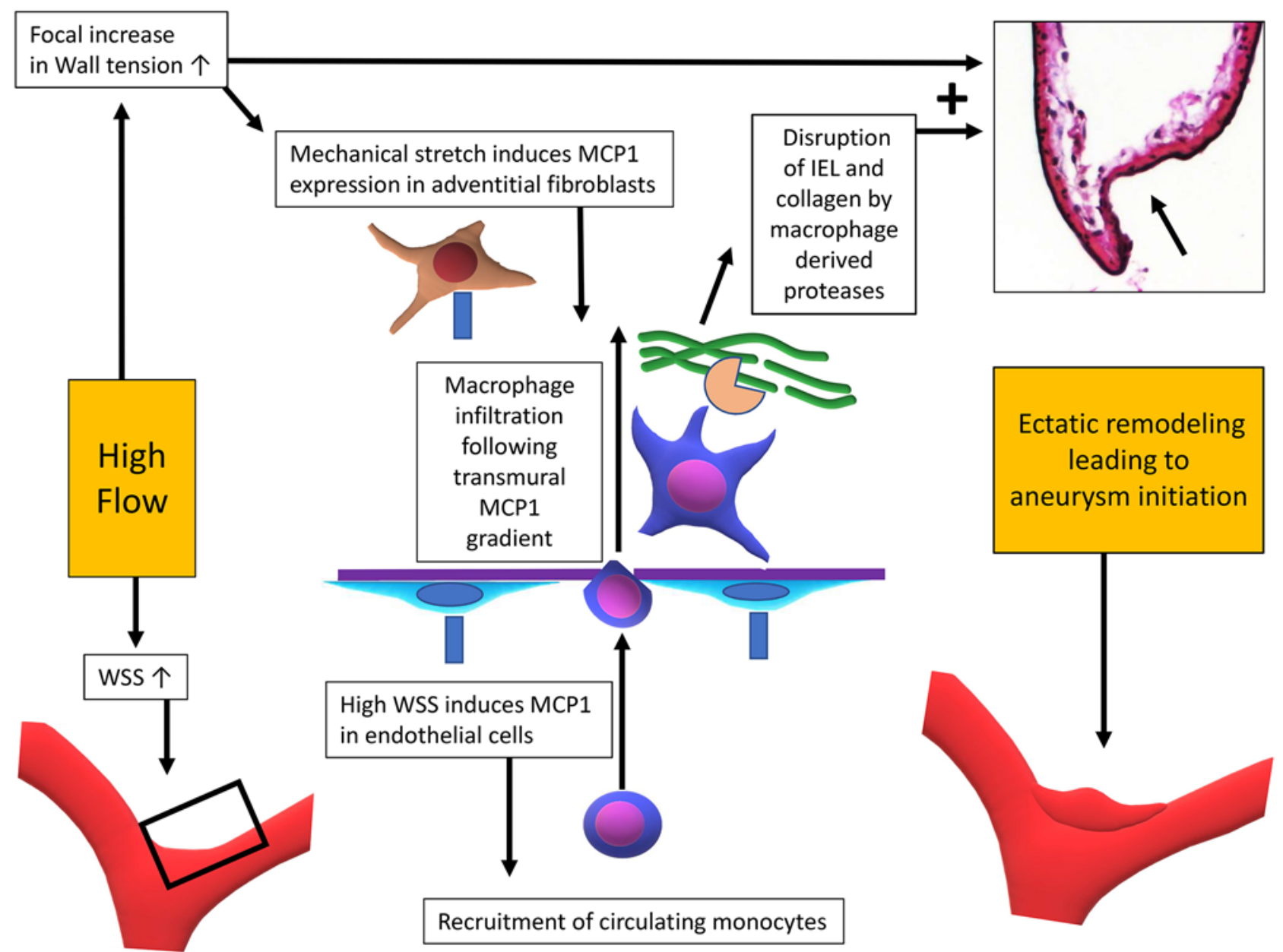

FIG. 3. High flow leads to an increase in WSS and the associated increase in vessel caliber will increase the WT. High WSS is sensed by the endothelium through the glycocalyx (light blue) and leads to the induction of MCP1 in the endothelial cells. The mechanical stretch of the arterial wall is, in turn, sensed by intramural cells and can induce MCP1 expression in fibroblasts. MCP1 plays a crucial role in the recruitment of circulating monocytes to the site of vessel remodeling, which appears to occur through the luminal endothelium and the arterial wall in mice but may occur mainly through adventitial capillaries in larger animals. These infiltrating macrophages, which migrate through the arterial wall following the chemotactic MCP1 signaling from the adventitia or lumen, secrete proteases that disrupt the IEL and the collagen matrix. Through this mechanism, high flow can induce IEL disruption, a key step in aneurysm initiation.

(Fig. 3) and once in the wall the macrophages produce proteases causing collagen degradation, ${ }^{4}$ it is logical that the macrophage infiltration eventually leads to IEL disruption as well as to disruption of the collagen matrix that is the load-bearing structure of the wall once elastic laminas are lost (see above).

\section{Flow-Triggered Inflammation-Mediated Remodeling in Aneurysm Growth}

Once the IEL is lost due to the infiltration of inflammatory cells, and the collagen matrix is damaged to the point of allowing the outward bulging of the initial aneurysm, the aneurysm may start to enlarge. This, however, requires that the aneurysm wall actively grows and synthesizes new matrix (discussed above). Mere prolonged proteolytic injury by infiltrating macrophages without concomitant remodeling of the collagen matrix would not lead to sub- stantial growth, but rather a rupture from a small, blisterlike bleb sometimes encountered in clinical practice.

SMCs of the IA wall synthesize the new collagen ${ }^{24,27}$ required for this active IA wall growth. These mural cells express receptors for several growth factors secreted by macrophages, e.g., transforming growth factor beta (TGFb) and platelet-derived growth factor B (PDGF-B), that stimulate SMC matrix synthesis and proliferation. ${ }^{26}$ That the macrophage activation constantly stimulates the SMCs, in addition to protease secretion, can explain why the aneurysm wall grows. Once initiated, the macrophage activation in the aneurysm wall amplifies itself through an autocrine feedback loop in which prostaglandin E2 $\left(\mathrm{PGE}_{2}\right)$ produced by cyclooxygenase 2 (COX2) activates the transcription factor nuclear factor kappa $b(\mathrm{NFkB})$ in other macrophages, leading to increased expression of MCP1 as well as COX2 by these cells ${ }^{2,8}$ (Fig. 4). This stimulates the recruitment of more macrophages to the 

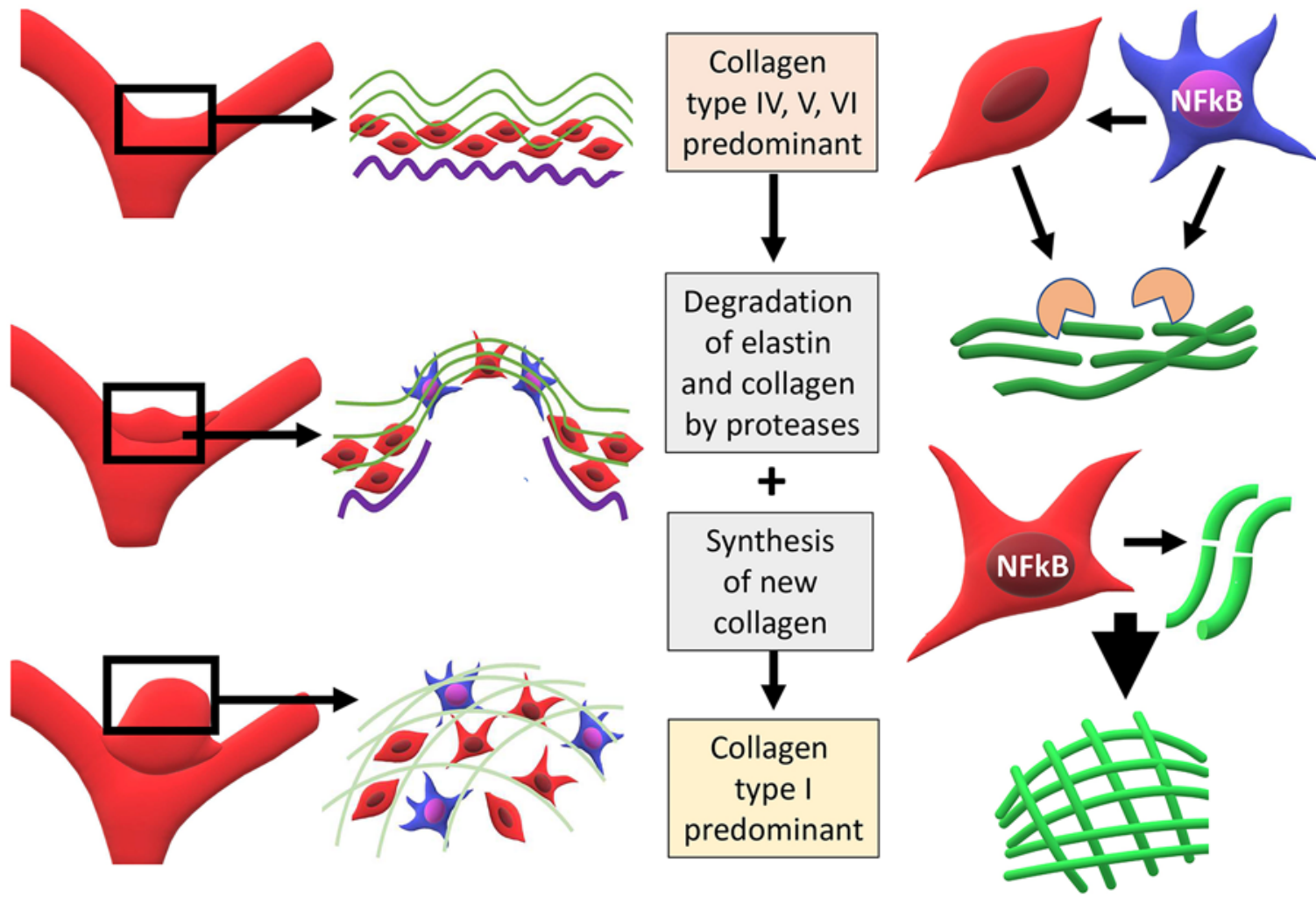

FIG. 4. Once initiated, the aneurysm will not grow unless there is active growth of the aneurysm wall and synthesis of new collagen. While loss of the elastic laminas (purple) enables the arterial wall to distend until the normally unloaded, curly collagen fibers (green) are distended, further growth of the aneurysm after initiation requires remodeling of the collagen because collagen does not distend. During this collagen remodeling, not only the orientation of the fibers but also the type of collagen in them changes (reviewed by Etminan et al., 201522). In parallel to the collagen remodeling, change in the phenotype of SMCs (red) occurs in the IA wall, in part related to proinflammatory signaling by infiltrating inflammatory cells (blue) that activates in SMC NFkB transcription factor, essential for arterial wall remodeling and aneurysm formation.

aneurysm wall, as well as NFkB activation in them. This amplification loop may explain the observation that wall remodeling initiated by high-flow conditions can continue even if the pathological flow is normalized.$^{52}$

Clinically, one of the most pertinent questions regarding the biology of aneurysm formation is how to stabilize small inceptions of aneurysms or small aneurysms and prevent them from growing to a size in which rupture becomes increasingly likely. ${ }^{22,31,72}$ The presence of MCP1 expression and macrophages $9,27,34,55$ in human IA walls implies that the same molecular mechanisms as in IA initiation might be involved in IA progression, at least in the formation of daughter aneurysms or so-called "secondary pouches" that tend to form in the IA sacs at regions with high WSS. ${ }^{15}$ In addition to high-WSS areas, MCP1 can be also induced in IA regions with low WSS. ${ }^{9}$ This is consistent with the observation that inflammation of the IA wall showed an associative trend with both high WSS and low WSS. ${ }^{11}$

In animals, activation of NFkB at the site of vessel remodeling is necessary for the IA to form..$^{5}$ This NFkB activation occurs through the COX2-PGE - -EP2-NFkB pathway as discussed above. ${ }^{2,8}$ Genome-wide gene expression analysis of ruptured and unruptured human IA walls has shown upregulation of multiple NFkB-regulated genes in ruptured IA walls, ${ }^{46}$ strongly implying that macrophageinduced NFkB activation is relevant in the wall remodeling of established human IAs, similar to the experimental models of induced-IA initiation and formation. ${ }^{2,5}$ The presence of COX2 expression in the human IA wall, 5,34 as well as of $\mathrm{PGE}_{2}$ receptor subtype EP2, further implies that the COX2-PGE 2 -EP2-NFkB-COX2 signaling pathway is involved in the growth and wall remodeling of human IAs ${ }^{2}$ similar to the experimental models of induced UIA formation. The seminal observation that drugs inhibiting COX2 activity, such as aspirin ${ }^{35}$ or nonsteroidal antiinflammatory drugs, appear to reduce the growth of UIAs in patients ${ }^{25}$ further supports this concept.

\section{Hyperplastic Remodeling as a Response to Increase in Mechanical Stretch: Role of Inflammation}

Once the initiated aneurysm starts to grow, its wall will be subjected to progressively higher wall tension (WT; Figs. 5-8). For the IA to remain unruptured, the wall has to adapt to the increased mechanical load. In general, the arterial wall adapts to chronically increased mechanical load through proliferation of the medial SMCs and collagen deposition, as noted in wall changes associated with 


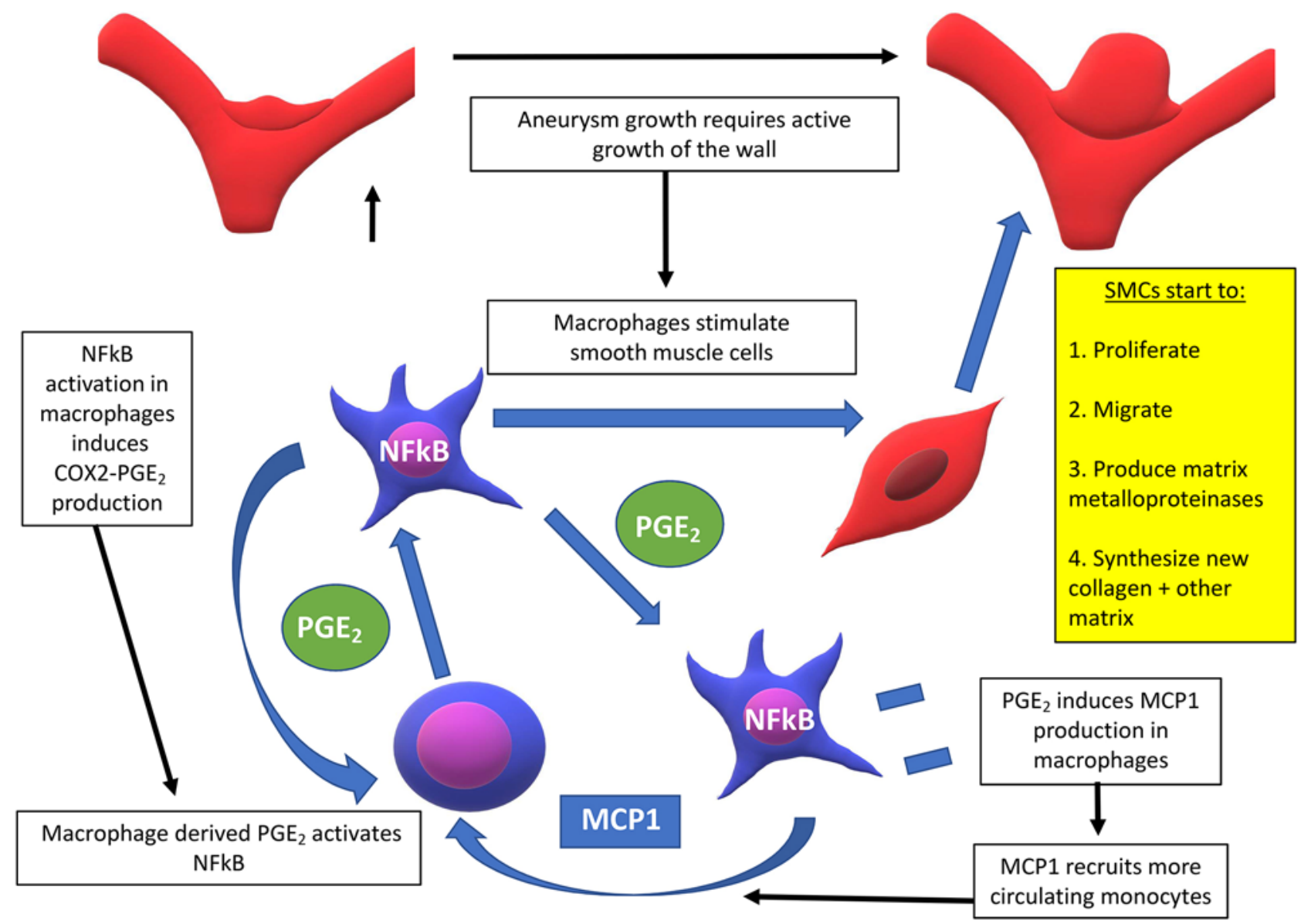

FIG. 5. SMCs of the IA wall that synthesize the new collagen express receptors for several growth factors secreted by macrophages, e.g., TGFb and PDGF-B, which stimulate SMC matrix synthesis and growth. That the macrophage activation constantly stimulates the SMCs, in addition to protease secretion, can explain why the aneurysm wall grows. Once initiated, the macrophage activation in the aneurysm wall amplifies itself through an autocrine feedback loop in which PGE 2 produced by COX2 activates NFkB in other monocytes/macrophages, leading to upregulation of MCP1 as well as COX2. This stimulates the recruitment of more macrophages to the aneurysm wall, as well as to NFkB activation in them, and maintains the chronic inflammation driving aneurysm growth.

hypertension. ${ }^{38}$ In cases in which this remodeling process is insufficient, the intramural cells may be exposed to supraphysiological stretch. The dynamics of this repair process following overstretch of this kind have been wellstudied in arterial balloon dilation injury models ${ }^{16,61}$ and are shown to depend on macrophages ${ }^{17}$ and NFkB activation in SMCs. ${ }^{74}$

The enlarging IA wall can adapt to this increase in WT through SMC proliferation and collagen remodeling, similar to the way an arterial wall responds to overstretching or chronic high pressure, provided that it has healthy SMCs. ${ }^{27}$ Many IA walls, however, have at least focal regions that show loss of SMCs. ${ }^{24,27,29}$ Moreover, in many IA walls the remaining SMCs turn into foam cells due to lipid ingestion, ${ }^{28,55}$ which impairs their normal function..$^{55}$ This can lead to a potentially dangerous scenario in which the aneurysm continues growing but has wall regions that are not able to adapt to the increase in WT caused by growth. The mechanisms of lipid accumulation in the IA wall are discussed in more detail in Ollikainen et al. ${ }^{55}$ and Frösen et al. ${ }^{28}$ Because endothelial dysfunction appears to be a key factor in promoting the accumulation of lipids in the IA wall, ${ }^{28,29,55}$ flow that regulates endothelial function is likely to affect the process of lipid-induced IA wall SMC dysfunction as well.

\section{Clinical Applications: Flow Modulation, Flow Modeling, and Multimodality Diagnostics}

Flow conditions in the human IA sac associate with focal changes in wall structure, ${ }^{12,39}$ as well as with histological changes of the IA wall, including inflammation. ${ }^{11}$ Moreover, additional data from a somewhat small number of cases suggest that flow conditions associate with collagen remodeling and strength of the IA wall.13,14

Measurement of flow conditions appears to hold great potential for the identification of 1) persons at risk of IA formation, 2) IAs that are likely to grow and should be followed attentively, and 3) unstable IAs that need an intervention. Flow conditions can be estimated with reasonable accuracy from 3D high-resolution angiograms using computational fluid dynamics (CFD), provided that the boundary 
Frösen et al.
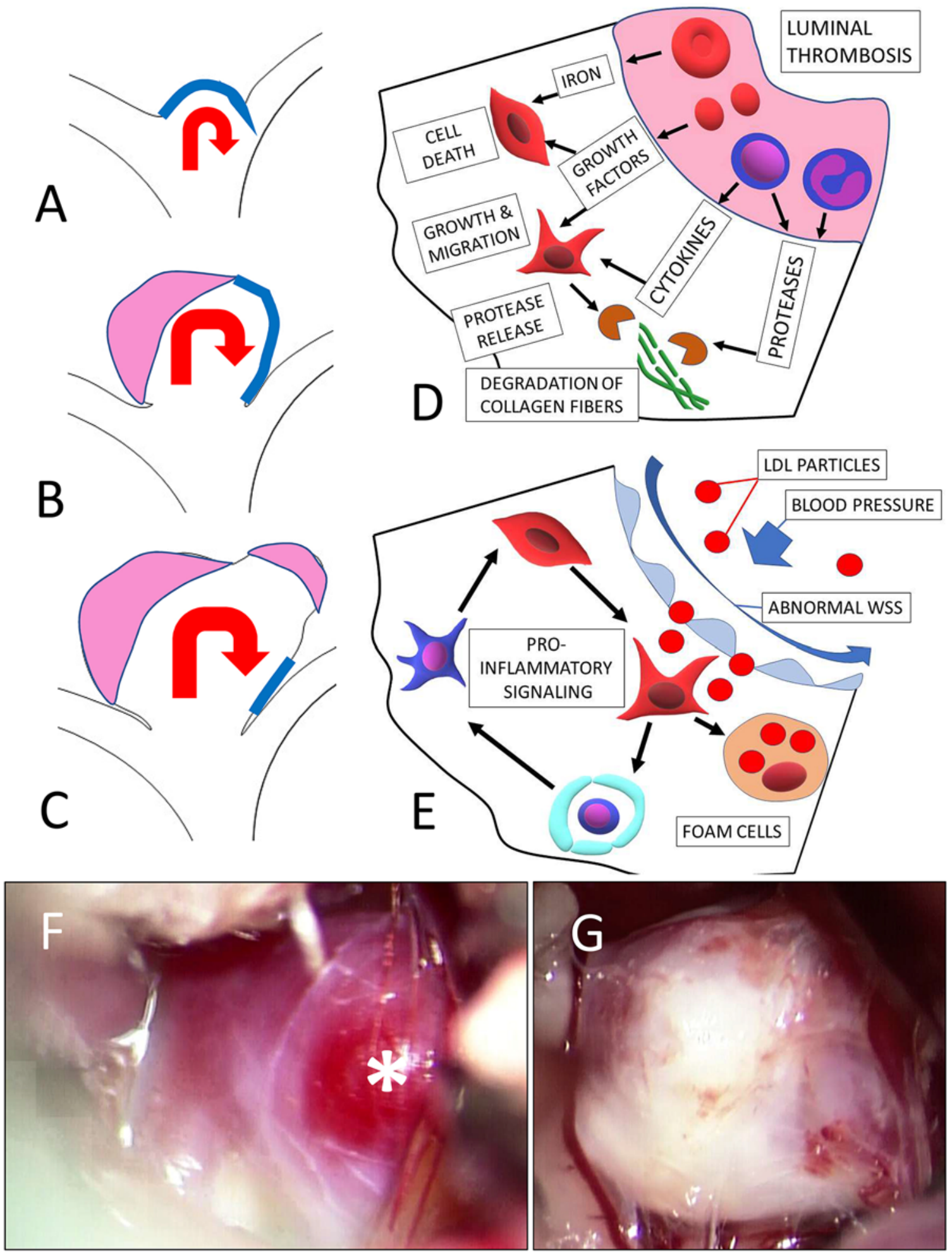

FIG. 6. When the aneurysm grows, flow conditions in the aneurysm lumen change because the luminal geometry changes. This is likely to change the flow-induced WSS, especially which areas of the wall are exposed to high WSS (blue line, A-C). Regions exposed to high flow are likely to undergo similar flow-induced inflammation-mediated remodeling as in aneurysm initiation, which in turn can explain focal growth of secondary pouches in the aneurysm wall at sites of high WSS. While in very small aneurysms a larger extent of the aneurysm wall is exposed to high WSS, in general, the more the aneurysm grows less of its surface area is exposed to high WSS. In addition to this, an increase in the aneurysm diameter is prone to cause regions with slower flow, which can predispose to luminal thrombosis (pink, B and C). Luminal thrombosis stimulates aneurysm wall remodeling through multiple mechanisms (reviewed in detail by Frösen et al., 2012). ${ }^{29}$ In brief, red blood cells (red), platelets (ellipsoids, red), and inflammatory cells, including neutrophils, are trapped in the thrombus and release cytokines and growth factors that stimulate proinflammatory phenotype and growth of SMCs in the aneurysm wall (D). This promotes wall remodeling that encompasses secretion of proteases that degrade the collagen matrix. FIG. 6. (continued) $\rightarrow$ 
FIG. 6. In addition to SMCs, the inflammatory cells in the luminal thrombus are also a source of collagen-degrading proteases. This thrombus-derived chronic proteolytic injury is especially relevant in aneurysms that have a decellularized wall devoid of mural cells capable of synthesizing new collagen. Flow-related factors predisposing to loss of mural cells include cytotoxic iron released from the degrading red blood cells of the luminal thrombus, as well as lipids that accumulate in the aneurysm wall to mural cells causing foam cell formation and eventually cell death. This lipid accumulation appears to be related to dysfunction of the luminal endothelium, which in turn can be explained by the nonphysiological flow conditions in the aneurysm lumen (E). Overall, through the effects of flow on endothelial function and thrombus formation, flow in the aneurysm lumen also affects wall remodeling by other mechanisms than the ones relevant in aneurysm formation. Consecutive exposure of different aneurysm wall regions to changing flow conditions resulting from aneurysm growth likely explains the high degree of heterogeneity on aneurysm wall structure observed during surgery (F and $\mathbf{G})$. That flow conditions associate with wall structure observed at surgery supports this concept. Asterisk indicates a focal region with a very thin wall. LDL $=$ low-density lipoprotein.

A

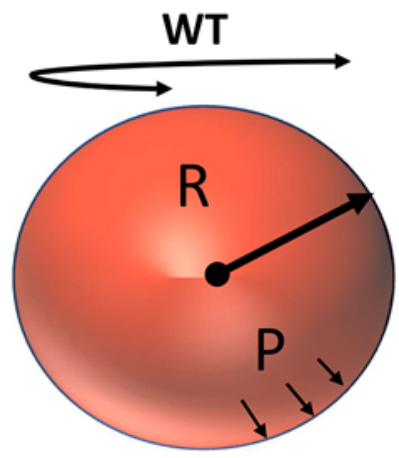

WT $=$ tension

$P=$ transmural pressure

$\mathrm{R}=$ radius

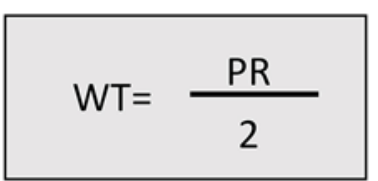

B

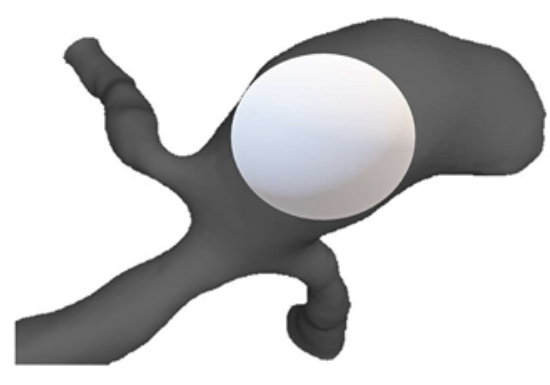

$$
\underset{\text { stress }}{\text { Intramural }}=\frac{\mathrm{WT}}{\mathrm{t}}=\frac{\text { (Transmural pressure } \mathrm{x} \text { radius) }}{2 \times \text { Wall thickness }}
$$

\section{$\mathrm{t}=$ wall thickness}
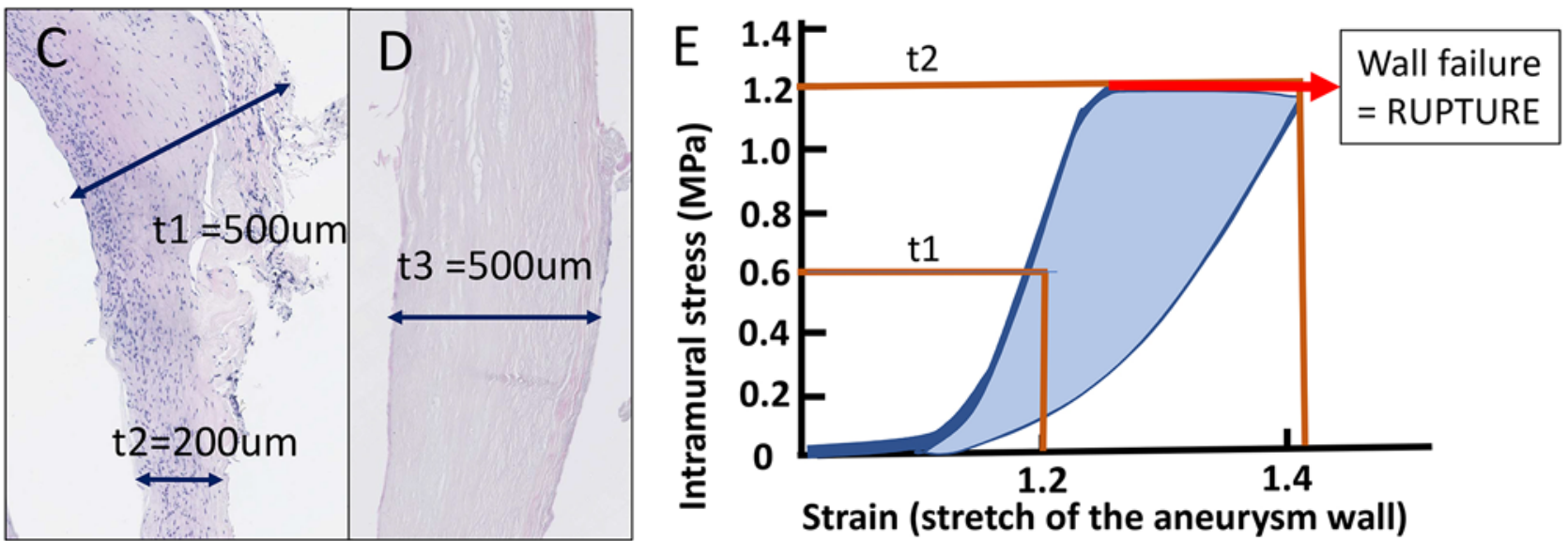

FIG. 7. When aneurysms grow, WT increases. This can be seen from a simple force balance in an idealized spherical shell using the law of Laplace (A). In a sphere, the WT acts around the circumference with similar loads acting on the components of the wall, such as collagen fibers and intramural cells. Although true IAs are rarely close to spherical (B, a sphere superimposed on the 3D geometry of an actual aneurysm in a patient), similar relationships exist between the local WT and geometry. This, in turn, means that in a growing aneurysm, as the diameter increases, the wall has to remodel to withstand higher WT. Moreover, because WT can also be defined through wall thickness and intramural stress (force pulling the wall components apart) as shown, it can be concluded that a simple increase in wall thickness will reduce intramural stress. In a wall with intact functional SMCs (C), for example, this can occur through collagen remodeling and proliferation of SMCs that may lead to significant focal increase in wall thickness (t1 vs $\mathrm{t} 2$ in C, H\&E-stained aneurysm wall). However, a wall with few healthy SMCs is less able to adapt (H\&E-stained example of a decellularized wall in D). This may explain, at least in part, the high variation observed in the strength of aneurysm wall tissue samples when stretched to failure. The stress-strain curve adapted from the measurements performed by Robertson et al. $2015^{58}$ and applicable for most aneurysm walls is shown in $\mathbf{E}$ (intramural stress determined as a first-order Piola-Kirkhoff tensor and the blue area corresponding to the range of curves measured from individual samples with the exception of a few outliers in the original data). Of note is the dependence of intramural stress on the wall thickness, which means that thinner regions ( $\mathrm{t} 1$ ) of the same aneurysm wall can be stretched to the maximum and close to rupture while thicker regions (t2) in the same aneurysm wall are not yet maximally loaded. 


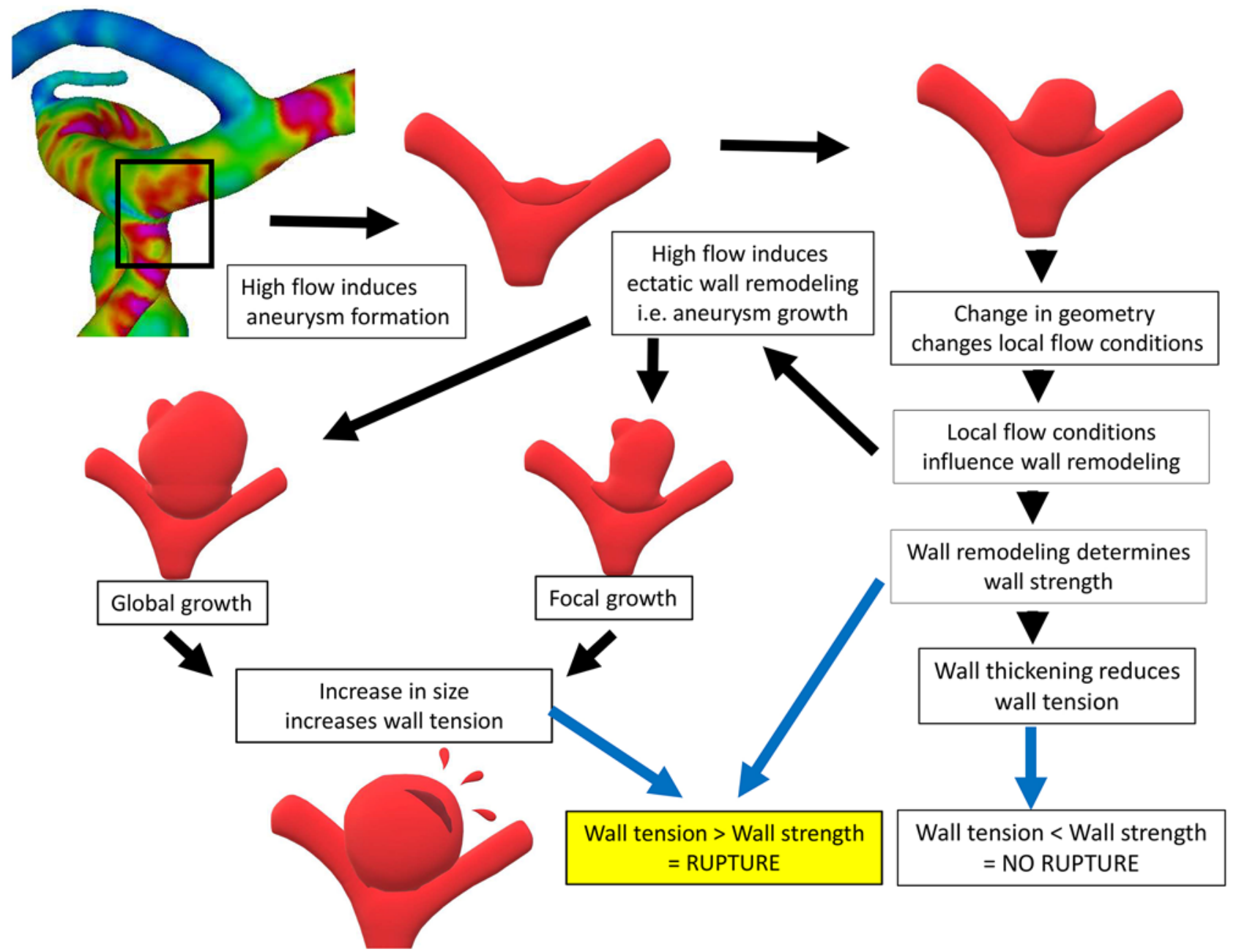

FIG. 8. IAs develop in humans mostly at arterial bifurcations in areas subjected to focal high WSS and high spatial gradients in WSS (example of WSS distribution in a CFD model of right ICA in upper left corner). The ectatic remodeling (mechanisms presented in Figs. 3-7) induced by high WSS predisposes to IA initiation and growth, which eventually will change the geometry of the aneurysm leading also to a change in flow conditions. Depending on what kind of flow conditions result from this aneurysm growth, the wall will remodel differently and focal growth (secondary pouch formation) or global growth may ensue. It is important to note that aneurysm growth will change the WT through the increase in size (discussed in Fig. 7) in addition to inducing wall remodeling. Wall remodeling, in turn, determines wall structure and strength, with great variation in the remodeling process, even within the unruptured population. These three factors (wall strength, wall structure, and wall load [tension]) are critical determinants of the structural integrity of the wall. Because the flow in the aneurysm sac can impact all of these, it is a key determinant of what the risk of rupture and natural history of a UIA will be.

conditions needed for the flow simulations are determined reasonably (see separate reviews on this topic in this issue). Although several studies have demonstrated how CFD can be used to differentiate ruptured and unruptured IAs with reasonable accuracy ${ }^{18}$ (as well as separate publications on the topic in this issue), from the biological point of view it is worth noting that many human IA walls have regions that have completely lost the endothelium. ${ }^{27}$ This will significantly impair the normal mechanobiological coupling between flow and wall remodeling, ${ }^{10,48}$ and raises questions as to whether such an IA wall is sensitive to flow-induced remodeling at all. To reliably determine what kind of flow conditions will lead to an unstable UIA, follow-up studies of UIAs with CFD performed at baseline are needed. Currently, there are few of this type of clinical series.
Although IAs in humans form preferentially at sites of high WSS, ${ }^{1}$ the fact that they do not form in all bifurcations exposed to high WSS and to all persons does seem to imply that a second factor is needed for IA initiation. In experimental models, concomitant elastase injury significantly promotes aneurysm formation at sites with flow conditions predisposing to IA formation. ${ }^{70}$ Because inflammatory cells, especially neutrophils, are an important source of elastase, ${ }^{29}$ it seems plausible that such a "second hit" in humans would take effect through activation of inflammatory cells and subsequent increase in elastase activity. Recently, involvement of the gut microbiome in a model of induced-IA formation has been reported. ${ }^{62}$ Even more recently, we have shown that severe periodontitis and gingival inflammation predisposes to IA formation 
and eventual aSAH in humans. ${ }^{33}$ Prior to this, the presence of oral bacteria-derived DNA had been shown in the IA wall. ${ }^{56}$ The biological mechanism by which the gut microbiome or periodontitis predisposes to IA formation remains to be shown, but clearly other factors besides flow are significant in the initiation and progression of UIAs.

In addition to acquired factors such as periodontitis, in some cases the "second hit" can be genetic, for example in polycystic kidney disease in which mutation in the polycystin gene affects the mechanobiological coupling of flow-endothelial cell interaction..$^{19}$ Of note, flow-driven vessel remodeling in arteriovenous fistulas was significantly increased in mice heterozygous for defective elastin gene. ${ }^{73}$ Identification of similar inherited "secondary triggers" will facilitate the identification of persons at risk of developing IAs, especially when coupled with flow modeling (CFD). Knowledge of the mechanobiological coupling between flow and wall remodeling, and identification of these environmental or genetic "secondary triggers," may also enable more efficient primary prevention of the disease, such as by treatment of periodontitis or by treatment of the flow-induced IA initiation with preventive drug therapy. Results from experimental models suggest that inhibitors of $\mathrm{COX} 2-\mathrm{PGE}_{2}$-EP2 signaling ${ }^{4,8}$ or PPARgamma inhibitors, ${ }^{63}$ for example, could be used for this purpose. Another potential target for drug therapy could be inhibition of the proteases mediating the flow-induced inflammation-driven remodeling.

\section{Conclusions}

High flow is an initiator of UIA formation and flow conditions also drive the wall remodeling that determines whether the aneurysm will remain stable, or progress and eventually rupture. Inflammatory cells mediate this flowinduced remodeling. Flow is not, however, the only factor involved in UIA initiation, nor the only factor determining UIA wall remodeling. Understanding the mechanobiological coupling of flow and aneurysm wall remodeling is the key to predicting the clinical course of an aneurysm. This will become increasingly more important because drug therapies that modulate flow-induced inflammatory remodeling are being developed.

\section{Acknowledgments}

Drs. Robertson, Cebral, and Frösen are grateful for support from NIH grant no. 1R01NS097457-01 from the National Institute of Neurological Disorders and Stroke (NINDS). Dr. Frösen was also supported by research grants from the Finnish Medical Foundation and Kuopio University Hospital (VTR grants). The funding agencies had no role in the design and conduct of the study, in the collection, management, analysis, or interpretation of the data, or in the preparation, review, or approval of the manuscript.

\section{References}

1. Alfano JM, Kolega J, Natarajan SK, Xiang J, Paluch RA, Levy EI, et al: Intracranial aneurysms occur more frequently at bifurcation sites that typically experience higher hemodynamic stresses. Neurosurgery 73:497-505, 2013

2. Aoki T, Fròsen J, Fukuda M, Bando K, Shioi G, Tsuji K, et al: Prostaglandin $\mathrm{E}_{2}-\mathrm{EP} 2-\mathrm{NF}-\kappa \mathrm{B}$ signaling in macrophages as a potential therapeutic target for intracranial aneurysms. Sci Signal 10:E6037, 2017
3. Aoki T, Kataoka H, Ishibashi R, Nozaki K, Egashira K, Hashimoto N: Impact of monocyte chemoattractant protein-1 deficiency on cerebral aneurysm formation. Stroke 40:942951, 2009

4. Aoki T, Kataoka H, Morimoto M, Nozaki K, Hashimoto N: Macrophage-derived matrix metalloproteinase-2 and -9 promote the progression of cerebral aneurysms in rats. Stroke 38:162-169, 2007

5. Aoki T, Kataoka H, Shimamura M, Nakagami H, Wakayama $\mathrm{K}$, Moriwaki T, et al: NF- $\kappa \mathrm{B}$ is a key mediator of cerebral aneurysm formation. Circulation 116:2830-2840, 2007

6. Aoki T, Nishimura M: The development and the use of experimental animal models to study the underlying mechanisms of CA formation. J Biomed Biotechnol 2011:535921, 2011

7. Aoki T, Nishimura M, Kataoka H, Ishibashi R, Nozaki K, Miyamoto S: Complementary inhibition of cerebral aneurysm formation by eNOS and nNOS. Lab Invest 91:619-626, 2011

8. Aoki T, Nishimura M, Matsuoka T, Yamamoto K, Furuyashiki T, Kataoka $\mathrm{H}$, et al: $\mathrm{PGE}_{2}-\mathrm{EP}_{2}$ signalling in endothelium is activated by haemodynamic stress and induces cerebral

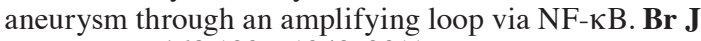
Pharmacol 163:1237-1249, 2011

9. Aoki T, Yamamoto K, Fukuda M, Shimogonya Y, Fukuda S, Narumiya S: Sustained expression of MCP-1 by low wall shear stress loading concomitant with turbulent flow on endothelial cells of intracranial aneurysm. Acta Neuropathol Commun 4:48, 2016

10. Aparício P, Mandaltsi A, Boamah J, Chen H, Selimovic A, Bratby M, et al: Modelling the influence of endothelial heterogeneity on the progression of arterial disease: application to abdominal aortic aneurysm evolution. Int J Numer Methods Biomed Eng 30:563-586, 2014

11. Cebral J, Ollikainen E, Chung BJ, Mut F, Sippola V, Jahromi $\mathrm{BR}$, et al: Flow conditions in the intracranial aneurysm lumen are associated with inflammation and degenerative changes of the aneurysm wall. AJNR Am J Neuroradiol 38:119-126, 2017

12. Cebral JR, Detmer F, Chung BJ, Choque-Velasquez J, Rezai $\mathrm{B}$, Lehto H, et al: Local hemodynamic conditions associated with focal changes in the intracranial aneurysm wall. AJNR Am J Neuroradiol 40:510-516, 2019

13. Cebral JR, Duan X, Chung BJ, Putman C, Aziz K, Robertson AM: Wall mechanical properties and hemodynamics of unruptured intracranial aneurysms. AJNR Am J Neuroradiol 36:1695-1703, 2015

14. Cebral JR, Duan X, Gade PS, Chung BJ, Mut F, Aziz K, et al: Regional mapping of flow and wall characteristics of intracranial aneurysms. Ann Biomed Eng 44:3553-3567, 2016

15. Cebral JR, Sheridan M, Putman CM: Hemodynamics and bleb formation in intracranial aneurysms. AJNR Am J Neuroradiol 31:304-310, 2010

16. Clowes AW, Clowes MM, Fingerle J, Reidy MA: Kinetics of cellular proliferation after arterial injury. V. Role of acute distension in the induction of smooth muscle proliferation. Lab Invest 60:360-364, 1989

17. Danenberg HD, Fishbein I, Gao J, Mönkkönen J, Reich R, Gati I, et al: Macrophage depletion by clodronate-containing liposomes reduces neointimal formation after balloon injury in rats and rabbits. Circulation 106:599-605, 2002

18. Detmer FJ, Fajardo-Jiménez D, Mut F, Juchler N, Hirsch S, Pereira VM, et al: External validation of cerebral aneurysm rupture probability model with data from two patient cohorts. Acta Neurochir (Wien) 160:2425-2434, 2018

19. Diagbouga MR, Morel S, Bijlenga P, Kwak BR: Role of hemodynamics in initiation/growth of intracranial aneurysms. Eur J Clin Invest 48:e12992, 2018

20. Dolan JM, Kolega J, Meng H: High wall shear stress and spatial gradients in vascular pathology: a review. Ann Biomed Eng 41:1411-1427, 2013 
21. Etminan N, Brown RD Jr, Beseoglu K, Juvela S, Raymond J, Morita A, et al: The unruptured intracranial aneurysm treatment score: a multidisciplinary consensus. Neurology 85:881-889, 2015

22. Etminan N, Rinkel GJ: Unruptured intracranial aneurysms: development, rupture and preventive management. Nat Rev Neurol 12:699-713, 2016

23. Franzoni M, Walsh MT: Towards the identification of hemodynamic parameters involved in arteriovenous fistula maturation and failure: a review. Cardiovasc Eng Technol 8:342-356, 2017

24. Frösen J: Smooth muscle cells and the formation, degeneration, and rupture of saccular intracranial aneurysm wall-a review of current pathophysiological knowledge. Transl Stroke Res 5:347-356, 2014

25. Frösen J, Björkman J, Ollikainen E, Kurtelius A, Tulamo R, Huttunen J, et al: Use of COX-2 inhibitor medication reduces the progression of intracranial aneurysms in patients. Cerebrovasc Dis 43 (Suppl 1):173, 2017 (Abstract)

26. Frösen J, Piippo A, Paetau A, Kangasniemi M, Niemelä M, Hernesniemi J, et al: Growth factor receptor expression and remodeling of saccular cerebral artery aneurysm walls: implications for biological therapy preventing rupture. Neurosurgery 58:534-541, 2006

27. Frösen J, Piippo A, Paetau A, Kangasniemi M, Niemelä M, Hernesniemi J, et al: Remodeling of saccular cerebral artery aneurysm wall is associated with rupture: histological analysis of 24 unruptured and 42 ruptured cases. Stroke 35:22872293, 2004

28. Frösen J, Tulamo R, Heikura T, Sammalkorpi S, Niemelä M, Hernesniemi J, et al: Lipid accumulation, lipid oxidation, and low plasma levels of acquired antibodies against oxidized lipids associate with degeneration and rupture of the intracranial aneurysm wall. Acta Neuropathol Commun 1: 71,2013

29. Frösen J, Tulamo R, Paetau A, Laaksamo E, Korja M, Laakso A, et al: Saccular intracranial aneurysm: pathology and mechanisms. Acta Neuropathol 123:773-786, 2012

30. Gentleman E, Lay AN, Dickerson DA, Nauman EA, Livesay GA, Dee KC: Mechanical characterization of collagen fibers and scaffolds for tissue engineering. Biomaterials 24:38053813,2003

31. Greving JP, Wermer MJ, Brown RD Jr, Morita A, Juvela S, Yonekura M, et al: Development of the PHASES score for prediction of risk of rupture of intracranial aneurysms: a pooled analysis of six prospective cohort studies. Lancet Neurol 13:59-66, 2014

32. Hall MR, Yamamoto K, Protack CD, Tsuneki M, Kuwahara G, Assi R, et al: Temporal regulation of venous extracellular matrix components during arteriovenous fistula maturation. J Vasc Access 16:93-106, 2015

33. Hallikainen J, Lindgren A, Savolainen J, Selander T, Jula A, Närhi M, et al: Periodontitis and gingival bleeding associate with intracranial aneurysms and risk of aneurysmal subarachnoid hemorrhage. Neurosurg Rev [epub ahead of print], 2019

34. Hasan D, Hashimoto T, Kung D, Macdonald RL, Winn HR, Heistad D: Upregulation of cyclooxygenase-2 (COX-2) and microsomal prostaglandin $\mathrm{E}_{2}$ synthase-1 (mPGES-1) in wall of ruptured human cerebral aneurysms: preliminary results. Stroke 43:1964-1967, 2012

35. Hasan DM, Mahaney KB, Brown RD Jr, Meissner I, Piepgras DG, Huston J, et al: Aspirin as a promising agent for decreasing incidence of cerebral aneurysm rupture. Stroke 42:3156-3162, 2011

36. Hill MR, Duan X, Gibson GA, Watkins S, Robertson AM: A theoretical and non-destructive experimental approach for direct inclusion of measured collagen orientation and recruitment into mechanical models of the artery wall. J Biomech 45:762-771, 2012
37. Humphrey JD: Vascular adaptation and mechanical homeostasis at tissue, cellular, and sub-cellular levels. Cell Biochem Biophys 50:53-78, 2008

38. Intengan HD, Schiffrin EL: Vascular remodeling in hypertension: roles of apoptosis, inflammation, and fibrosis. Hypertension 38:581-587, 2001

39. Kadasi LM, Dent WC, Malek AM: Colocalization of thinwalled dome regions with low hemodynamic wall shear stress in unruptured cerebral aneurysms. J Neurosurg 119:172-179, 2013

40. Kanematsu Y, Kanematsu M, Kurihara C, Tada Y, Tsou TL, van Rooijen N, et al: Critical roles of macrophages in the formation of intracranial aneurysm. Stroke 42:173-178, 2011

41. Kappelle LJ, Eliasziw M, Fox AJ, Barnett HJ: Small, unruptured intracranial aneurysms and management of symptomatic carotid artery stenosis. Neurology 55:307-309, 2000

42. Kondo S, Hashimoto N, Kikuchi H, Hazama F, Nagata I, Kataoka H: Cerebral aneurysms arising at nonbranching sites. An experimental Study. Stroke 28:398-404, 1997

43. Korja M, Lehto H, Juvela S: Lifelong rupture risk of intracranial aneurysms depends on risk factors: a prospective Finnish cohort study. Stroke 45:1958-1963, 2014

44. Koseki H, Miyata H, Shimo S, Ohno N, Mifune K, Shimano $\mathrm{K}$, et al: Two diverse hemodynamic forces, a mechanical stretch and a high wall shear stress, determine intracranial aneurysm formation. Transl Stroke Res [epub ahead of print], 2019

45. Kotowski M, Naggara O, Darsaut TE, Nolet S, Gevry G, Kouznetsov E, et al: Safety and occlusion rates of surgical treatment of unruptured intracranial aneurysms: a systematic review and meta-analysis of the literature from 1990 to 2011. J Neurol Neurosurg Psychiatry 84:42-48, 2013

46. Kurki MI, Häkkinen SK, Frösen J, Tulamo R, von und zu Fraunberg M, Wong G, et al: Upregulated signaling pathways in ruptured human saccular intracranial aneurysm wall: an emerging regulative role of Toll-like receptor signaling and nuclear factor- $\kappa \mathrm{B}$, hypoxia-inducible factor-1A, and ETS transcription factors. Neurosurgery 68:1667-1676, 2011

47. Langille BL: Arterial remodeling: relation to hemodynamics. Can J Physiol Pharmacol 74:834-841, 1996

48. Langille BL, O'Donnell F: Reductions in arterial diameter produced by chronic decreases in blood flow are endothelium-dependent. Science 231:405-407, 1986

49. Lasjaunias P, Piske R, Terbrugge K, Willinsky R: Cerebral arteriovenous malformations (C. AVM) and associated arterial aneurysms (AA). Analysis of 101 C. AVM cases, with 37 AA in 23 patients. Acta Neurochir (Wien) 91:29-36, 1988

50. Lindgren AE, Koivisto T, Björkman J, von Und Zu Fraunberg M, Helin K, Jääskeläinen JE, et al: Irregular shape of intracranial aneurysm indicates rupture risk irrespective of size in a population-based cohort. Stroke 47:1219-1226, 2016

51. Lindgren AE, Räisänen S, Björkman J, Tattari H, Huttunen $\mathrm{J}$, Huttunen T, et al: De novo aneurysm formation in carriers of saccular intracranial aneurysm disease in eastern Finland. Stroke 47:1213-1218, 2016

52. Meng H, Metaxa E, Gao L, Liaw N, Natarajan SK, Swartz $\mathrm{DD}$, et al: Progressive aneurysm development following hemodynamic insult. J Neurosurg 114:1095-1103, 2011

53. Meng H, Wang Z, Hoi Y, Gao L, Metaxa E, Swartz DD, et al: Complex hemodynamics at the apex of an arterial bifurcation induces vascular remodeling resembling cerebral aneurysm initiation. Stroke 38:1924-1931, 2007

54. Naggara ON, Lecler A, Oppenheim C, Meder JF, Raymond $\mathrm{J}$ : Endovascular treatment of intracranial unruptured aneurysms: a systematic review of the literature on safety with emphasis on subgroup analyses. Radiology 263:828-835, 2012

55. Ollikainen E, Tulamo R, Lehti S, Lee-Rueckert M, Hernesniemi J, Niemelä M, et al: Smooth muscle cell foam cell forma- 
tion, apolipoproteins, and ABCA1 in intracranial aneurysms: implications for lipid accumulation as a promoter of aneurysm wall rupture. J Neuropathol Exp Neurol 75:689-699, 2016

56. Pyysalo MJ, Pyysalo LM, Pessi T, Karhunen PJ, Öhman JE: The connection between ruptured cerebral aneurysms and odontogenic bacteria. J Neurol Neurosurg Psychiatry 84:1214-1218, 2013

57. Rapoport RM, Murad F: Endothelium-dependent and nitrovasodilator-induced relaxation of vascular smooth muscle: role of cyclic GMP. J Cyclic Nucleotide Protein Phosphor Res 9:281-296, 1983

58. Robertson AM, Duan X, Aziz KM, Hill MR, Watkins SC, Cebral JR: Diversity in the strength and structure of unruptured cerebral aneurysms. Ann Biomed Eng 43:1502-1515, 2015

59. Robertson AM, Watton PN: Mechanobiology of the arterial wall, in Becker SM, Kuznetsov AV (eds): Transport in Biological Media. New York: Elsevier, 2013, pp 275-347.

60. Räisänen S, Frösen J, Kurki MI, Huttunen T, Huttunen J, Koivisto T, et al: Impact of young age on the presentation of saccular intracranial aneurysms: population-based analysis of 4082 patients. Neurosurgery 82:815-823, 2018

61. Shi Y, Pieniek M, Fard A, O’Brien J, Mannion JD, Zalewski A: Adventitial remodeling after coronary arterial injury. Circulation 93:340-348, 1996

62. Shikata F, Shimada K, Sato H, Ikedo T, Kuwabara A, Furukawa $\mathrm{H}$, et al: Potential influences of gut microbiota on the formation of intracranial aneurysm. Hypertension 73:491496, 2019

63. Shimada K, Furukawa H, Wada K, Korai M, Wei Y, Tada $Y$, et al: Protective role of peroxisome proliferator-activated receptor- $\gamma$ in the development of intracranial aneurysm rupture. Stroke 46:1664-1672, 2015

64. Sigovan M, Rayz V, Gasper W, Alley HF, Owens CD, Saloner D: Vascular remodeling in autogenous arterio-venous fistulas by MRI and CFD. Ann Biomed Eng 41:657-668, 2013

65. Tanweer O, Wilson TA, Metaxa E, Riina HA, Meng H: A comparative review of the hemodynamics and pathogenesis of cerebral and abdominal aortic aneurysms: lessons to learn from each other. J Cerebrovasc Endovasc Neurosurg 16:335-349, 2014

66. Tarbell JM, Weinbaum S, Kamm RD: Cellular fluid mechanics and mechanotransduction. Ann Biomed Eng 33:17191723,2005

67. Thompson RC, Steinberg GK, Levy RP, Marks MP: The management of patients with arteriovenous malformations and associated intracranial aneurysms. Neurosurgery 43:202-212, 1998

68. Tutino VM, Mandelbaum M, Choi H, Pope LC, Siddiqui A, Kolega J, et al: Aneurysmal remodeling in the circle of Willis after carotid occlusion in an experimental model. J Cereb Blood Flow Metab 34:415-424, 2014
69. Morita A, Kirino T, Hashi K, Aoki N, Fukuhara S, Hashimoto N, et al: The natural course of unruptured cerebral aneurysms in a Japanese cohort. N Engl J Med 366:2474-2482, 2012

70. Wada K, Makino H, Shimada K, Shikata F, Kuwabara A, Hashimoto T: Translational research using a mouse model of intracranial aneurysm. Transl Stroke Res 5:248-251, 2014

71. Wagenseil JE, Mecham RP: Elastin in large artery stiffness and hypertension. J Cardiovasc Transl Res 5:264-273, 2012

72. Wiebers DO, Whisnant JP, Huston J III, Meissner I, Brown RD Jr, Piepgras DG, et al: Unruptured intracranial aneurysms: natural history, clinical outcome, and risks of surgical and endovascular treatment. Lancet 362:103-110, 2003

73. Wong CY, Rothuizen TC, de Vries MR, Rabelink TJ, Hamming JF, van Zonneveld AJ, et al: Elastin is a key regulator of outward remodeling in arteriovenous fistulas. Eur J Vasc Endovasc Surg 49:480-486, 2015

74. Yoshida T, Yamashita M, Horimai C, Hayashi M: Smooth muscle-selective inhibition of nuclear factor- $\kappa \mathrm{B}$ attenuates smooth muscle phenotypic switching and neointima formation following vascular injury. J Am Heart Assoc 2:e000230, 2013

75. Zhou J, Li YS, Chien S: Shear stress-initiated signaling and its regulation of endothelial function. Arterioscler Thromb Vasc Biol 34:2191-2198, 2014

\section{Disclosures}

The authors report no conflict of interest concerning the materials or methods used in this study or the findings specified in this paper.

\section{Author Contributions}

Conception and design: all authors. Acquisition of data: Frösen, Robertson, Aoki. Analysis and interpretation of data: all authors. Drafting the article: all authors. Critically revising the article: all authors. Reviewed submitted version of manuscript: all authors. Approved the final version of the manuscript on behalf of all authors: Frösen. Administrative/technical/material support: Frösen, Cebral, Aoki. Study supervision: Frösen.

\section{Correspondence}

Juhana Frösen: Kuopio University Hospital, Kuopio, Finland. juhana.frosen@kuh.fi. 